\title{
Identification of a p53-repressed gene module in breast cancer cells
}

\author{
Takafumi Miyamoto $^{1}$, Chizu Tanikawaㄹ, Varalee Yodsurang5, Yao-Zhong Zhang ${ }^{2}$, \\ Seiya Imoto ${ }^{3}$, Rui Yamaguchi ${ }^{2}$, Satoru Miyano², Hidewaki Nakagawa ${ }^{4}$ and Koichi \\ Matsuda $^{5}$ \\ ${ }^{1}$ Laboratory of Genome Technology, Human Genome Center, Institute of Medical Science, The University of Tokyo, Tokyo, \\ Japan \\ ${ }^{2}$ Laboratory of DNA Information Analysis, Human Genome Center, Institute of Medical Science, The University of Tokyo, \\ Tokyo, Japan \\ ${ }^{3}$ Division of Health Medical Data Science, Health Intelligence Center, Institute of Medical Science, The University of Tokyo, \\ Tokyo, Japan \\ ${ }^{4}$ Laboratory for Genome Sequencing Analysis, RIKEN Center for Integrative Medical Sciences, Tokyo, Japan \\ ${ }^{5}$ Laboratory of Clinical Genome Sequencing, Department of Computational Biology and Medical Sciences, Graduate School \\ of Frontier Sciences, The University of Tokyo, Tokyo, Japan
}

Correspondence to: Koichi Matsuda, email: kmatsuda@k.u-tokyo.ac.jp

Keywords: p53, breast cancer, transcriptome analysis, adriamycin, gene module

Received: January 27, $2017 \quad$ Accepted: May 28, $2017 \quad$ Published: July 26, 2017

Copyright: Miyamoto et al. This is an open-access article distributed under the terms of the Creative Commons Attribution License 3.0 (CC BY 3.0), which permits unrestricted use, distribution, and reproduction in any medium, provided the original author and source are credited.

\section{ABSTRACT}

The p53 protein is a sophisticated transcription factor that regulates dozens of target genes simultaneously in accordance with the cellular circumstances. Although considerable efforts have been made to elucidate the functions of p53-induced genes, a holistic understanding of the orchestrated signaling network repressed by p53 remains elusive. Here, we performed a systematic analysis to identify simultaneously regulated p53-repressed genes in breast cancer cells. Consequently, 28 genes were designated as the p53-repressed gene module, whose gene components were simultaneously suppressed in breast cancer cells treated with Adriamycin. A ChIPseq database showed that p53 does not preferably bind to the region around the transcription start site of the p53-repressed gene module elements compared with that of p53-induced genes. Furthermore, we demonstrated that p21/CDKN1A plays a pivotal role in the suppression of the p53-repressed gene module in breast cancer cells. Finally, we showed that appropriate suppression of some genes belonging to the p53-repressed gene module contributed to a better prognosis of breast cancer patients. Taken together, these findings disentangle the gene regulatory network underlying the built-in p53-mediated tumor suppression system.

\section{INTRODUCTION}

Breast cancer is the most common cancer in females worldwide. Accumulating evidence has revealed that many genes are involved in the carcinogenesis of breast cancer. A loss of heterozygosity in chromosomes $1,3 p, 6 q$, 7q, 8, 9p, 10q, 11q, 13q, 16q, 17, 18q, 20q, 22q, or X has been detected as genetic abnormalities in breast cancers $[1,2]$. In addition, several genetic syndromes, including hereditary breast and/or ovarian cancer syndrome (caused by BRCA1 and BRCA2 mutations) [3]], Cowden syndrome (caused by PTEN gene mutation) [4, 5], hereditary diffuse gastric cancer (caused by $\mathrm{CDH1}$ gene mutation) [6], LiFraumeni syndrome (caused by $p 53$ gene mutation) [7], and Peutz-Jeghers syndrome (caused by STK11 gene mutation) [8], have been reported to increase the risk of breast cancer. Among those genes whose germline mutation predisposes a person to breast cancer, the transcription factor gene $p 53$ is the second most frequently mutated gene (24\% in the Catalog of Somatic Mutations in Cancer (COSMIC) database) after PIK3CA (27\% in COSMIC) in breast cancer [9]. Thus, p53 is one of the key molecules that prevent the development of breast cancer as well as other types of cancer. 
The p53 protein is at the core of the signaling network that governs the cell-intrinsic tumor suppression system. Enormous research efforts have revealed the diversity of p53-regulated cellular functions (e.g., cell cycle arrest, apoptosis, senescence, and metabolic reprogramming) [10]. Befitting its role in maintaining cellular fitness by regulating these cellular functions, p53 induces an appropriate set of target genes in response to cellular stressors. To date, over one hundred genes have been reported to be transactivated by p53 (p53induced genes) [11]. In contrast, genes whose expression is suppressed by p53 (p53-repressed genes) are poorly known. Indeed, p53-repressed genes account for less than $20 \%$ of the p53 targetome that has been reported [11]. Because p53 mediates the transactivation of many target genes in accordance with their intrinsic function, it is a fascinating avenue of p53 research to accumulate knowledge on p53-repressed genes and their cellular functions. In addition, it is important to understand the intrinsic gene regulatory mechanism, particularly the set of genes that is coexpressed as a gene module to facilitate p53-regulated cellular processes appropriately under specific conditions.

In this study, we identified 44 genes as p53repressed genes in breast cancer using a combination of three different transcriptome analyses. Among them, 28 genes were classified into the p53-repressed gene module, whose gene elements were suppressed simultaneously in response to genotoxic stress in breast cancer cells. Many of p53-repressed genes are involved in cell cycle regulation. In addition, we found that p53 suppressed the expression of these genes, at least in part, via the p21/ CDKN1A-mediated system. Finally, we showed that downregulation of p53-repressed genes is associated with the favorable prognosis of breast cancer.

\section{RESULTS}

\section{Identification of p53-repressed gene candidates}

To comprehend the gene network repressed by p53, we utilized three independent sets of transcriptome analyses: (i) microarray of Adriamycin (ADR)-treated p53 knockout MCF10A breast epithelial cells (MCF10A $p 53^{-/-}$) and their wild-type counterparts (MCF10A $p 53^{+/+}$) (MCF10A cells dataset, Supplementary Table S1); (ii) high-throughput RNA sequencing (RNA-seq) data from the mammary gland of X-ray-irradiated $p 53^{-/-}$mice and genetically matched $p 53^{+/+}$mice ( $p 53$ mice dataset, Supplementary Table S2) [50]; and (iii) RNA-seq of breast invasive carcinoma harboring wild-type $p 53$ (p53WT) and p53 mutations ( $553 \mathrm{Mt}$ ) obtained from the Cancer Genome Atlas (TCGA) database (TCGA-BRCA) [12] (TCGA dataset, Supplementary Table S3).
To identify p53-repressed genes, we set a discrimination criterion for each dataset (Figure 1A1C). As a result, 1,739 genes, 373 genes, and 6,451 genes were identified as candidates for p53-repressed genes in the MCF10A cells dataset, p53 mice dataset, and TCGA dataset, respectively (Figure 1A-1C). We subsequently combined these datasets to detect p53repressed genes with higher fidelity. Consequently, 44 genes were selected as p53-repressed gene candidates (Figure 1D, Supplementary Figure S1). Among them, 17 genes (AURKB [13], BIRC5 [14], CCNA2 [15], CCNB1 [15], CCNB2 [16], CDC20 [17], CDCA8 [18], CENPA [19], CEP55 [20], KIF23 [21], LMNB1 [22], MCM5 [23], PLK1 [24], RACGAP1 [25], RRM2 [26], TOP2A [27], and $U B E 2 C[28])$ have been reported as being p53-repressed genes with experimental verification.

\section{Identification of a p53-repressed gene module in breast cancer cells under genotoxic conditions}

Because p53 can regulate the expression of multiple genes concurrently, it is important to understand a set of genes that are co-regulated under specific conditions [29]. Thus, we tried to detect a p53-repressed gene module that responded to genotoxic stress in breast cancer cells. For this purpose, we performed quantitative PCR (qPCR) using seven breast cancer cell lines. Four cell lines (HBL-100, HBC4, MCF-7, and ZR-75-1) had wild-type p53, whereas the others (T-47D, SK-BR-3, and BT-549) harbored a p53 mutation. ADR treatment induced major p53 targets, $p 21 / C D K N 1 A$ and MDM2 mRNA, in wildtype p53 cells, whereas the mRNA expression levels were maintained at low levels in cancer cells harboring a p53 mutation, regardless of the ADR treatment (Supplementary Figure S2A). Taken together, these results indicated that the transactivation activity of p53 was inactivated in cancer cells that have mutant $\mathrm{p} 53$.

Next, from the 44 p53-repressed gene candidates (Figure 1D), we selected the genes whose expression level was diminished after ADR treatment in at least two of the four cell lines with wild-type p53, but not in the three cell lines that harbored the p53 mutation. A $\log _{2}-$ fold change value $\leq-2$ was a criterion for a gene to be considered as repressed by ADR treatment. Consistent with the qPCR results, we selected 32 genes as candidates for $\mathrm{p} 53$-repressed genes that displayed a $\log _{2}$-fold change value of $\leq-2$ in ADR-treated breast cancer cell lines (Figure 2). PLK1, one of the p53-repressed gene products, exhibited similar expression dynamics in terms of mRNA and protein levels, indicating the validity of our screening methods (Supplementary Figure S3). In the case of HBL100 cells, ADR treatment did not repress any of the 44 genes, although $p 21 / C D K N 1 A$ and MDM2 mRNA was strongly upregulated after ADR treatment (Supplementary Figure S2A). One potential reason is that HBL-100 cells 
expressed the SV40 viral antigen [30], which might have affected p53-mediated gene repression [31].

To determine whether these 32 genes were repressed by ADR treatment in a p53-dependent manner, we performed siRNA-mediated p53 knockdown in HBC4 cells harboring wild-type $p 53$. Knockdown of $p 53$ resulted in the suppression of $p 21 / C D K N 1 A$ mRNA expression, which indicated that $\mathrm{p} 53$ function was perturbed in $p 53$ knockdown cells (Supplementary Figure S2B). Consistent with this finding, p53 knockdown completely abrogated ADR-induced suppression of all 32 genes (Figure 3 and Supplementary Figure S4). Next, we examined the effect of the transduction of adenovirus expressing wild-type p53 (Ad-p53) into T-47D cells harboring a p53 mutation. The $\log _{2}$-fold change value $\leq-2$ was a criterion for a gene to be considered as repressed by exogenous p53. Ad-p53 transduction revealed that the expression of 28 of the 32 genes was repressed by the ectopic expression of p53 (Figure 4). Overall, we identified 28 genes that were simultaneously suppressed in breast cancer cells exposed to genotoxic stress (hereafter referred to as the p53-repressed gene module). Gene ontology analysis by DAVID Functional Annotation tool [32] revealed that the p53-repressed gene module was mainly assigned to regulation of the cell cycle (Supplementary Figure S5).

\section{Examination of gene expression dynamics of the p53-repressed gene module across tissues}

Although p53 is ubiquitously expressed, the set of genes transactivated by p53 differed across tissues [33]. To determine whether the p53-repressed gene module identified in breast cancer cells is a finite module or a tissue-specific one under genotoxic conditions, we analyzed the RNA-seq dataset of various tissues of X-rayirradiated $p 53^{-/-}$mice and genetically matched $p 53^{+/+}$mice [50]. Multi-tissue analysis revealed that the p53-repressed
A
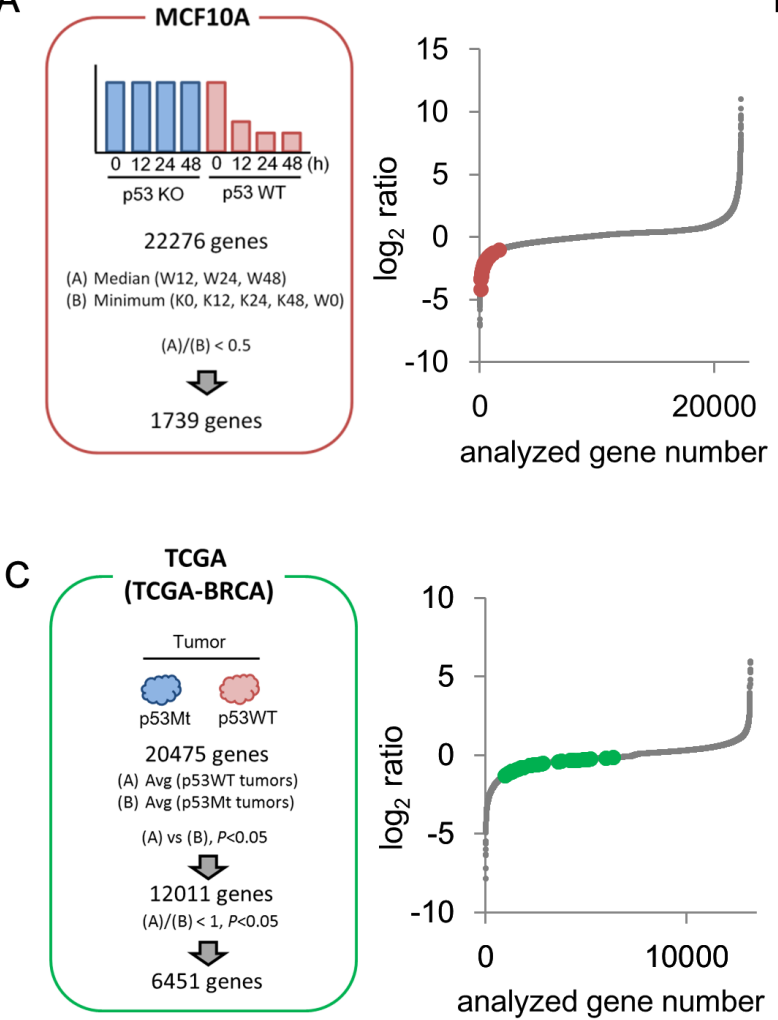

B
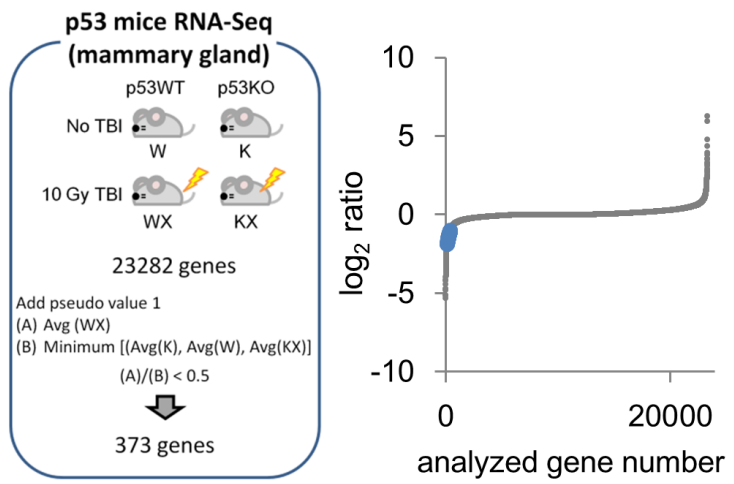

D

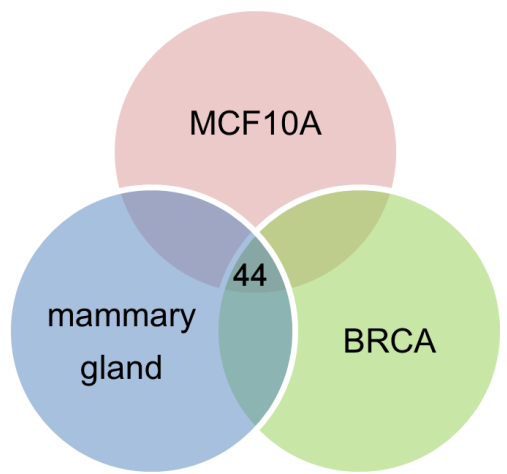

Figure 1: Identification of p53-repressed gene candidates. A. Schematic of the MCF10A cells dataset screen is shown. MCF10A $p 53^{+/+}$cells and MCF10A $p 53^{-/}$cells were treated with $0.5 \mu \mathrm{g} / \mathrm{ml}$ ADR for 2 hours, then cultured with fresh medium by indicated time. Subsequently, the cells were subjected to transcriptome analysis. Red dots indicate 44 common p53-repressed gene candidates identified in (D). W: MCF10A $p 53^{+/+}$cells, K: MCF10A $p 53^{-/}$cells. B. Schematic of the $p 53$ mice dataset screen is shown. $p 53^{+/+}$and $p 53^{-/}$female mice (10 weeks old) were irradiated at $10 \mathrm{~Gy}$ (total body irradiation [TBI]). Twenty-four hours after irradiation, the gene expression level in the mammary gland was analyzed using RNA-seq. Blue dots indicate 44 common p53-repressed gene candidates identified in (D). C. Schematic of the TCGA dataset (BRCA: Breast Invasive Carcinoma) screen is shown. Green dots indicate 44 common p53-repressed gene candidates identified in (D). D. Venn diagram displaying the overlap between the three datasets obtained from A., B., and C. 
MCF-7 cells

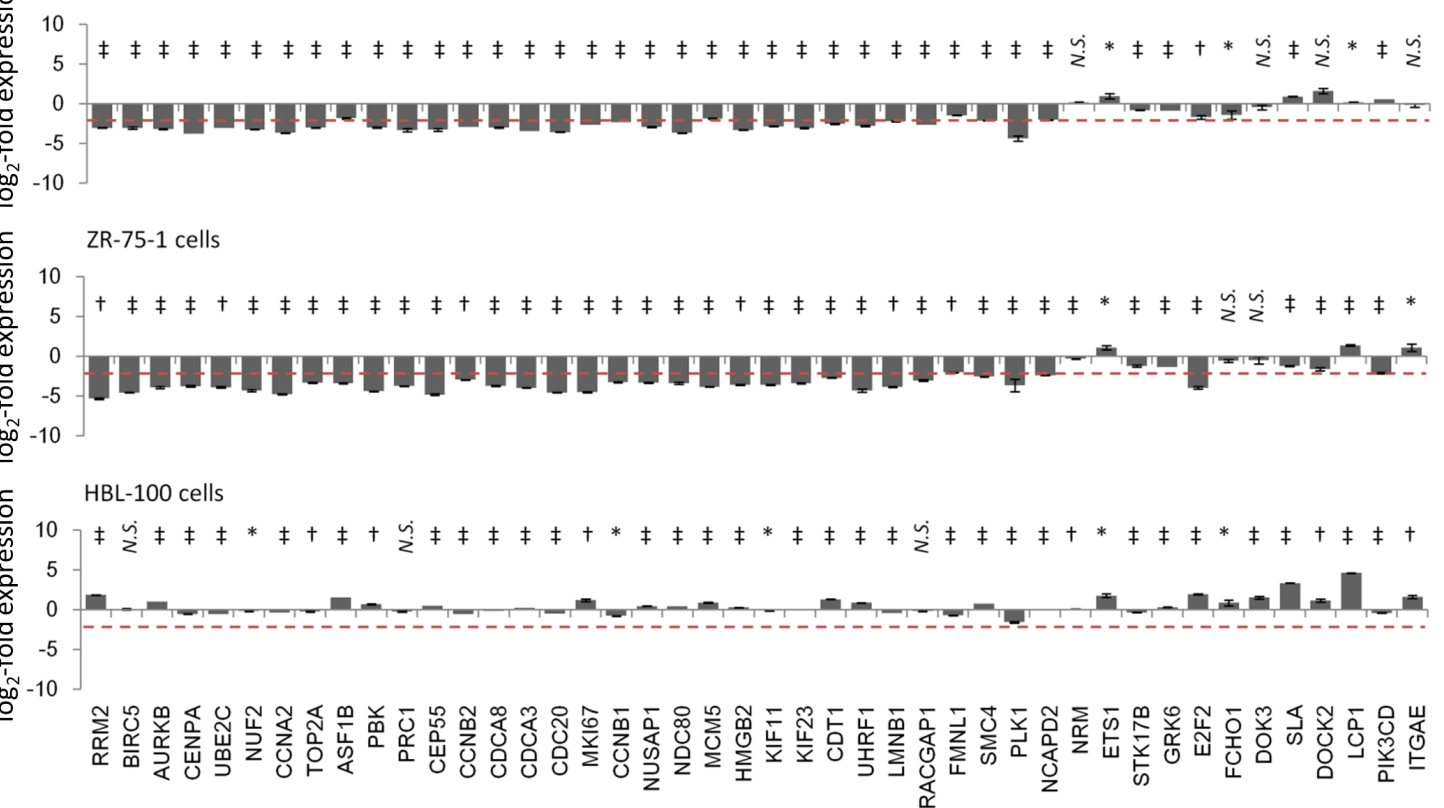

B

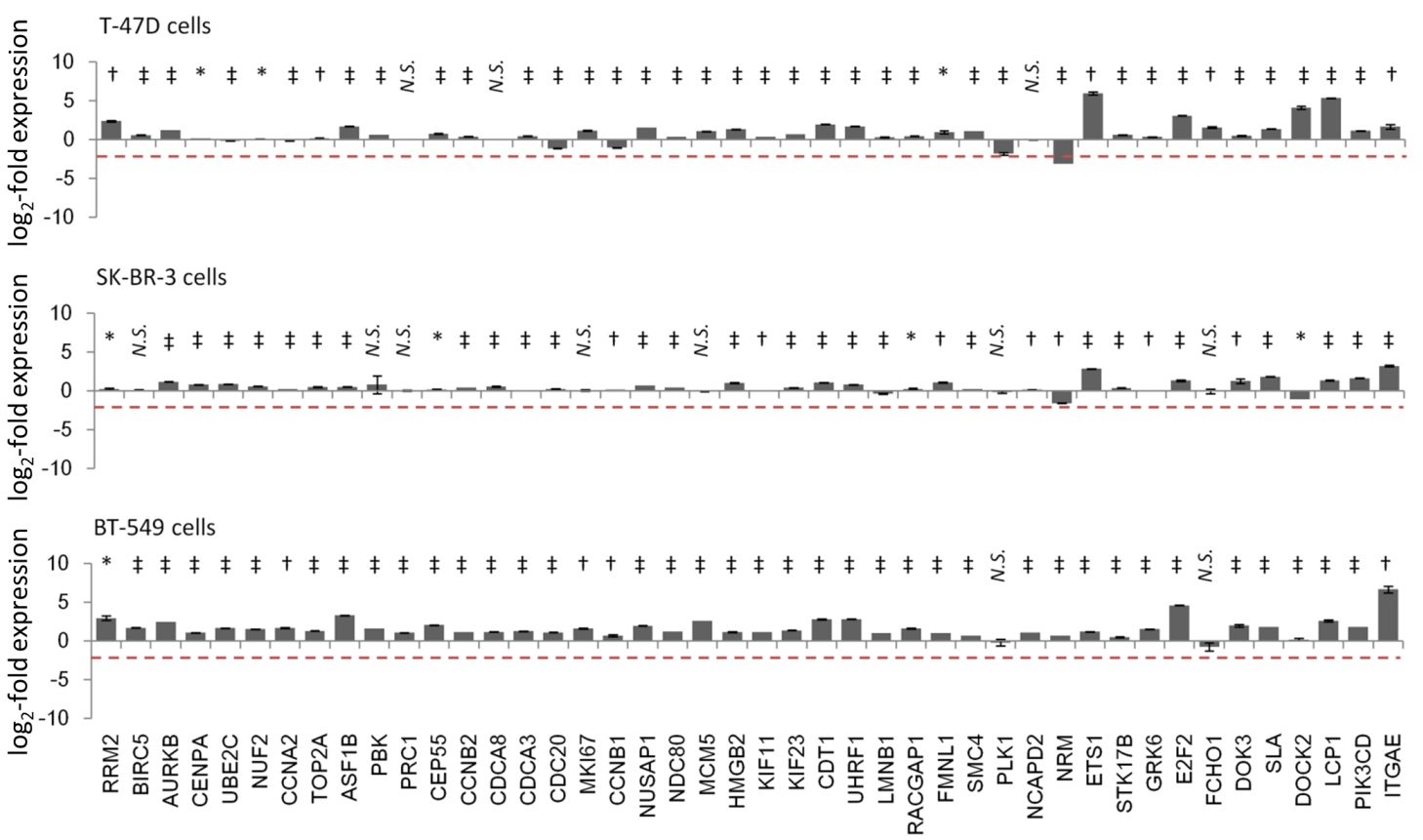

common p53-repressed genes

Figure 2: Identification of common p53-repressed genes in ADR-treated breast cancer cells by ADR treatment. Indicated breast cancer cells [(A) cells harboring wild-type p53, (B) cells harboring p53 mutations] were treated with $2 \mu \mathrm{g} / \mathrm{ml}$ ADR for 2 hours. Fortyeight hours after treatment, the mRNA expression level of the indicated genes was determined using qPCR and the $\log _{2}$-fold change of mRNA expression from ADR-treated compared to untreated cells were calculated using the $\Delta \Delta \mathrm{Ct}$ method. The graph shows the $\log _{2}$-fold change of mRNA expression in ADR-treated cells. The data are presented as the mean $\pm \mathrm{SD}$ from three independent experiments. The red

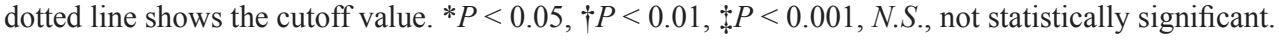


gene module elements were suppressed in many tissues of irradiated $p 53^{+/+}$mice compared with non-irradiated $p 53^{+/+}$ mice (Figure 5A). Importantly, simultaneous suppression of the p53-repressed gene module was observed in the mammary gland, uterus, and thymus but not in other tissues in irradiated- $p 53^{+/+}$mice (Figure $5 \mathrm{~A}$ ), indicating that the regulation of the p53-repressed gene module was highly tissue-specific. In contrast, simultaneous suppression of the p53-repressed gene module was not observed in $p 53^{-/-}$mice (Figure 5B).

\section{Analysis of the occupancy of p53 around the TSS of p53-repressed gene module elements}

In response to various cellular stressors, p53 binds to the consensus motif ( $\mathrm{p} 53$ response element, p53RE) around target genes, resulting in the induction of $\mathrm{p} 53$ -

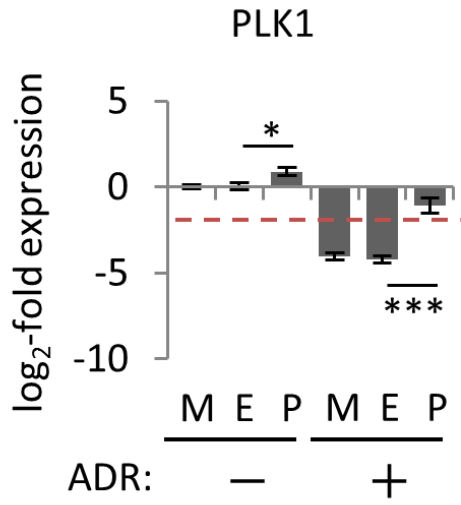

CCNB2

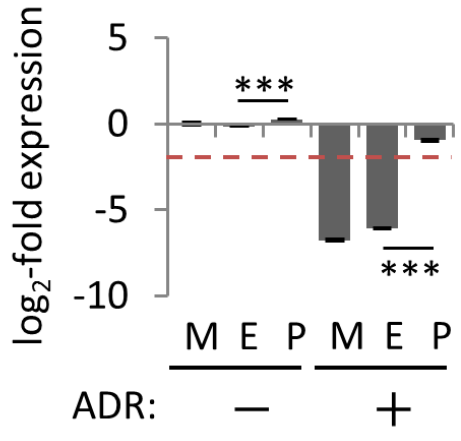

CEP55

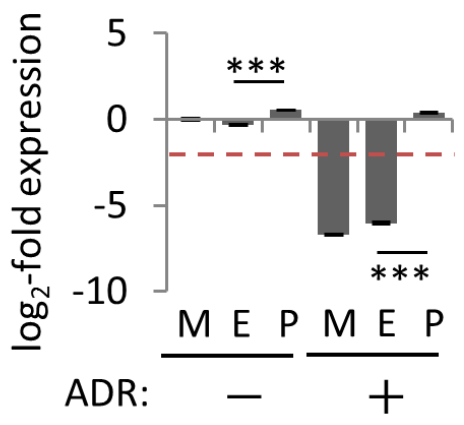

BIRC5

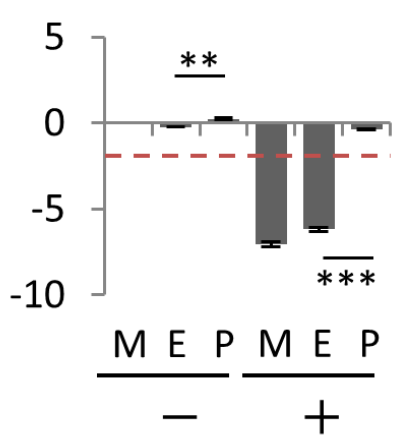

UBE2C

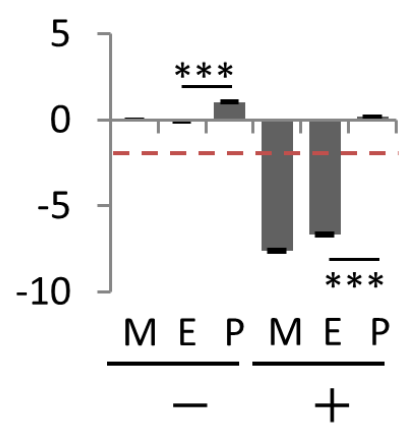

CDCA8

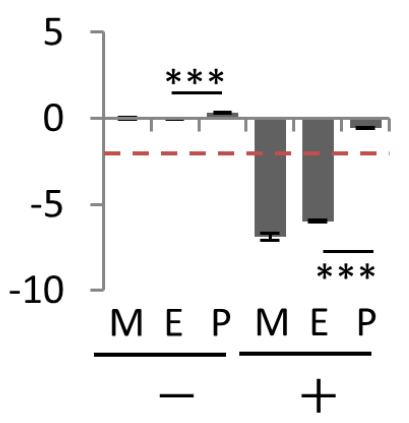

RACGAP1

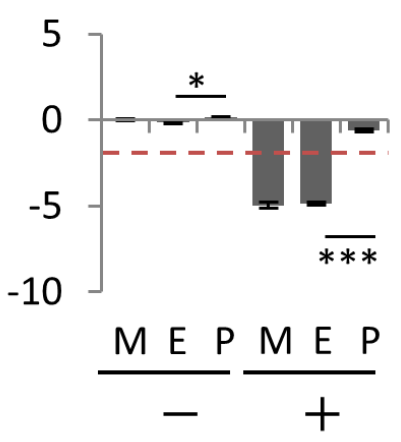

CCNB1

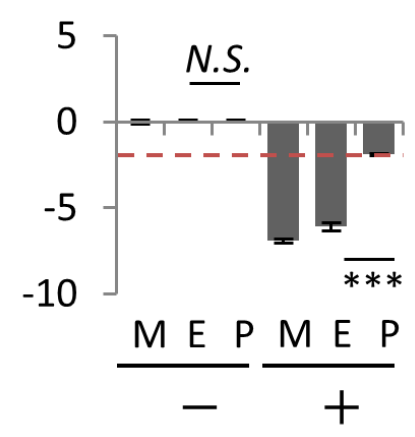

CENPA

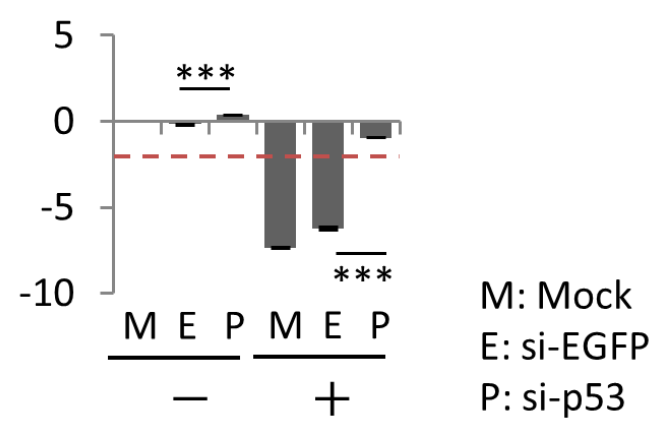

Figure 3: Effect of p53 knockdown on the regulation of common p53-repressed genes. At 24 hours after transfection of the indicated siRNA, HBC4 cells were treated with $2 \mu \mathrm{g} / \mathrm{ml}$ ADR for 2 hours. Forty-eight hours after treatment, the mRNA expression level of the indicated genes was determined using $\mathrm{qPCR}$ and the $\log _{2}$-fold change of mRNA expression against the control condition (Mock, no ADR treatment) was calculated using the $\Delta \Delta \mathrm{Ct}$ method. The data are presented as the mean $\pm \mathrm{SD}$ from three independent experiments. The red dotted line shows cutoff value. $* P<0.05, * * P<0.01, * * * P<0.001, N$.S., not statistically significant. Representative data (9 genes) are presented. Additional data are shown in Supplementary Figure S4. 
induced genes [11]. However, the requirement of p53 binding to p53REs or a region around the transcription start site (TSS) for p53-mediated suppression remains a controversial topic $[34,35]$. To test whether the p53repressed gene module contained p53-binding regions around the TSS, we assessed p53 ChIP-seq datasets

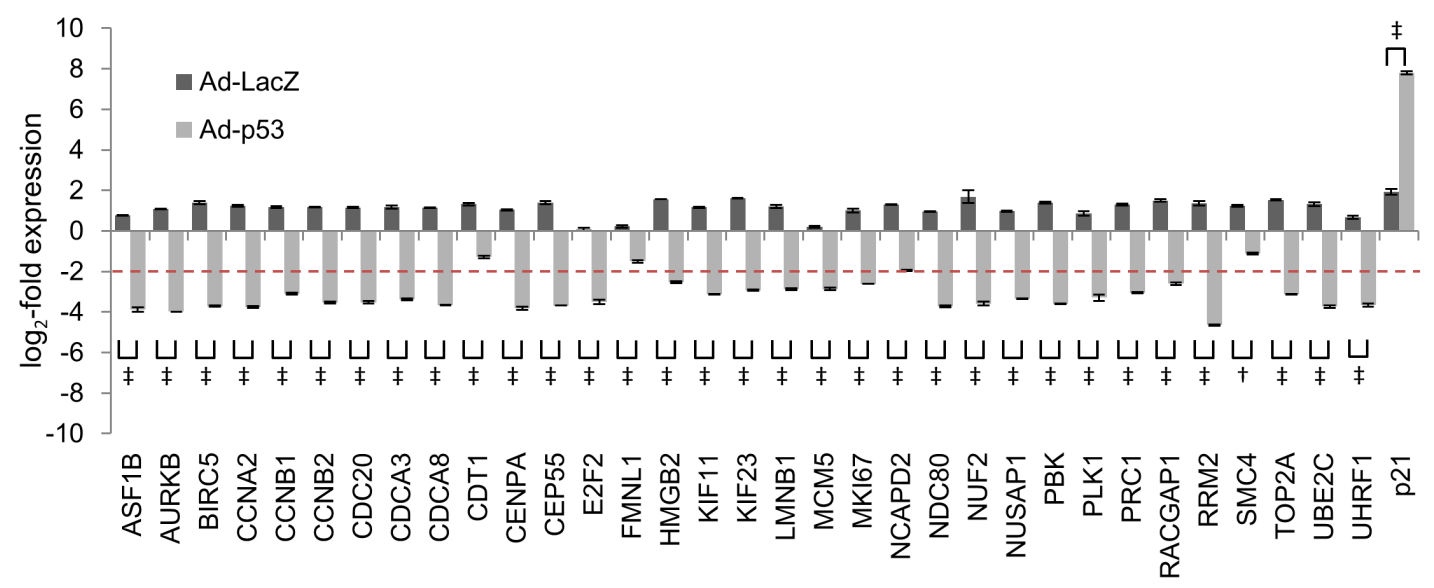

Figure 4: Effect of Ad-p53 on the regulation of common p53-repressed genes. T-47D cells were infected with adenoviruses expressing either LacZ (Ad-LacZ) or wild-type p53 (Ad-p53) at multiplicities of infection (MOI) of 40. At 48 hours after transduction, the mRNA expression level of indicated genes was determined using qPCR and the $\log _{2}$-fold change of mRNA expression against the control condition (no adenovirus transduced cells) were calculated using the $\Delta \Delta \mathrm{Ct}$ method. The graph shows the $\log _{2}$-fold change of mRNA expression in Ad-LacZ-transduced cells and Ad-p53-transduced cells. The data are presented as the mean \pm SD from three independent experiments. The red dotted line shows the cutoff value. $\uparrow P<0.01, \ddagger P<0.001$.

A

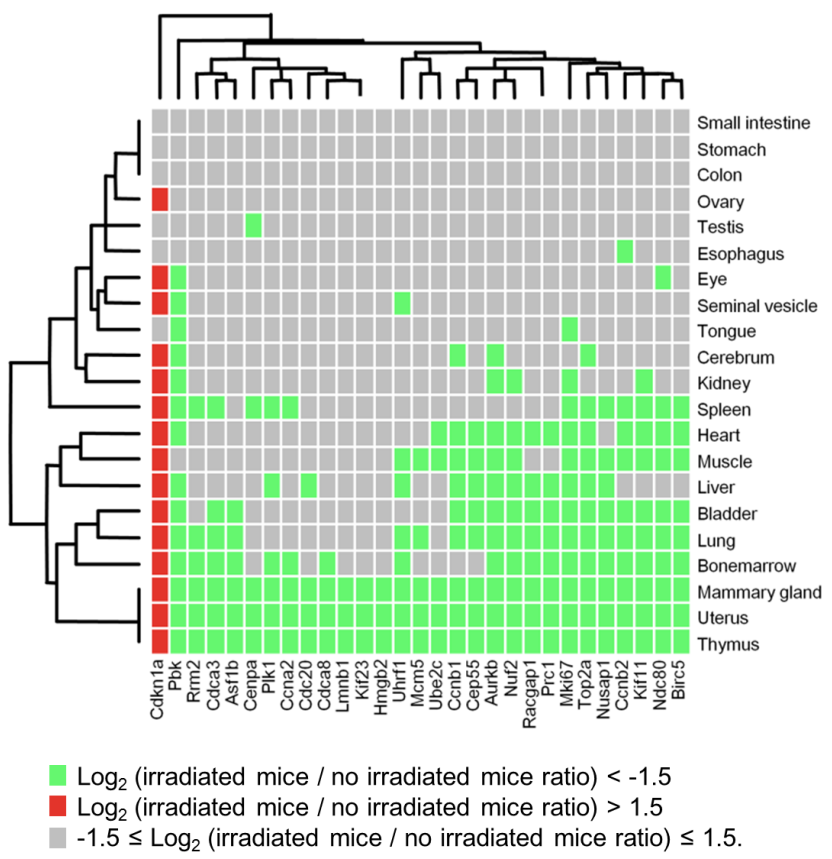

B

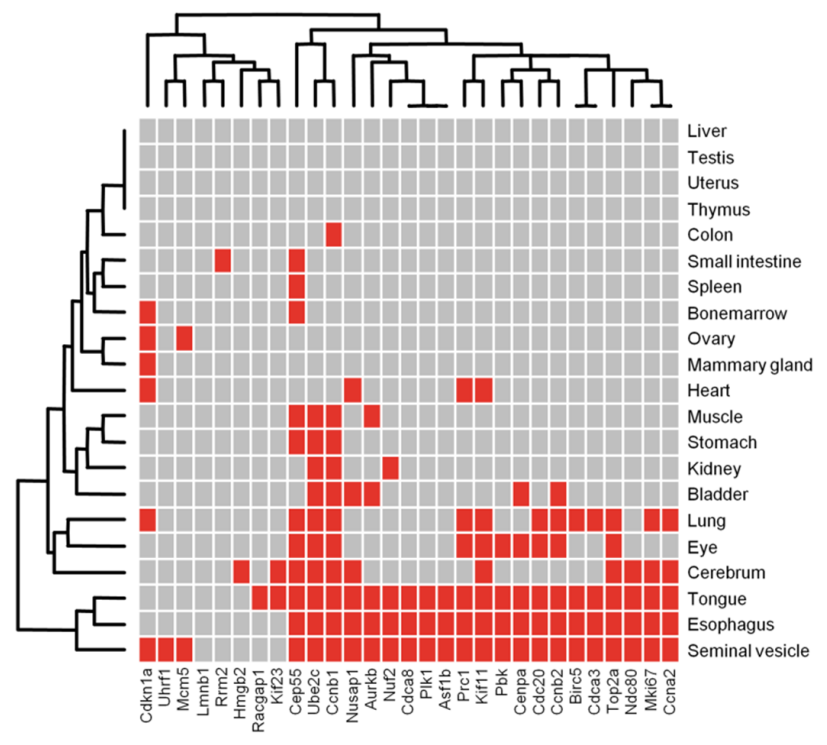

$\log _{2}$ (irradiated mice / no irradiated mice ratio) $>1.5$ $-1.5 \leq \log _{2}$ (irradiated mice / no irradiated mice ratio) $\leq 1.5$.

Figure 5: Systemic regulation of the p53-repressed gene module. A. $p 53^{+/+}$mice were irradiated at 10 Gy (total body irradiation). Twenty-four hours after irradiation, the change in the indicated gene expression level was calculated as the ratio of irradiated $p 53^{+/+}$mice to non-irradiated $p 53^{+/+}$mice. Each tissue, $n=3$ (mammary gland and ovary, $n=2$ ). B. $p 53^{-/-}$mice were irradiated at 10 Gy (total body irradiation). Twenty-four hours after irradiation, the change in the indicated gene expression level was calculated as the ratio of irradiated $p 53^{-/-}$mice to non-irradiated $p 53^{-/-}$mice. Each tissue, $n=3$ (mammary gland and ovary, $n=2$ ). 
obtained using cells that had been treated with ADR (http://www.targetgenereg.org/) [36]. For this analysis, 183 previously reported genes were classified into p53induced genes (Supplementary Table S4). Five different p53 ChIP-seq datasets in the database showed that p53 preferably bound to a promoter region ( $\pm 2 \mathrm{~kb}$ from a TSS) of p53-induced genes (78 genes, $42.6 \%$ ) rather than the p53-repressed gene module (1 gene, 3.7\%) (Figure 6A), indicating that p53-induced genes were significantly enriched for p53REs ( $p=0.0000154$, Fisher's exact test). To further examine the prevalence of p53REs around the TSS of p53-induced genes, we examined p53 ChIP-seq datasets in the public database ReMap [37]. Analysis of the promoter region of p53REs showed that 46.4\% (85 genes) of the p53-induced genes and $21.4 \%$ (6 genes) of the p53-repressed gene module contained p53REs ( $p=$
0.0139, Fisher's exact test) (Figure 6B and 6C). Similar results were also observed in a region within $\pm 10 \mathrm{~kb}$ from the TSS of p53-induced genes $(63.4 \%, 116$ genes) and p53-repressed gene module $(35.7 \%, 10$ genes $)(p=0.007$, Fisher's exact test) (Figure 6B and 6C). Taken together, these results suggested that p53 could regulate the p53repressed gene module via an indirect mechanism.

\section{p21/CDKN1A is a key molecule for regulating the p53-repressed gene module}

Although $p 21 / C D K N 1 A$ is the preferred target gene of $\mathrm{p} 53$, accumulating evidence indicated that p21/CDKN1A plays a pivotal role in p53-mediated repression of various downstream target genes [15, 38-
A

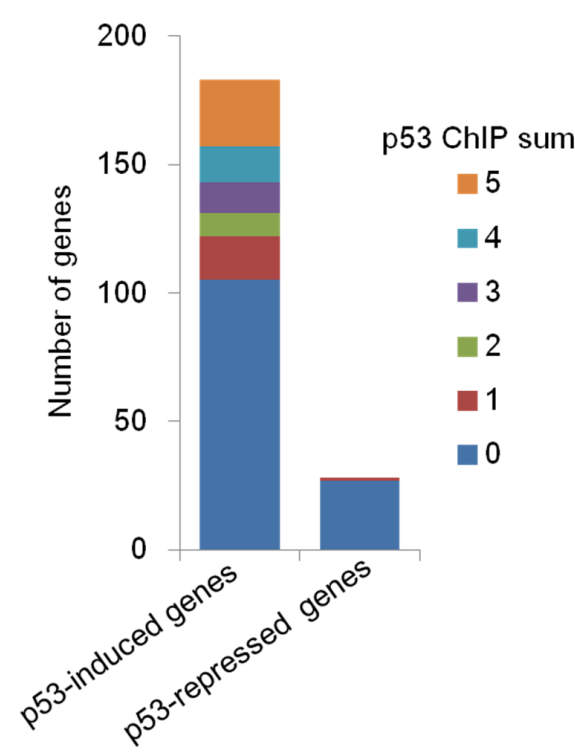

B

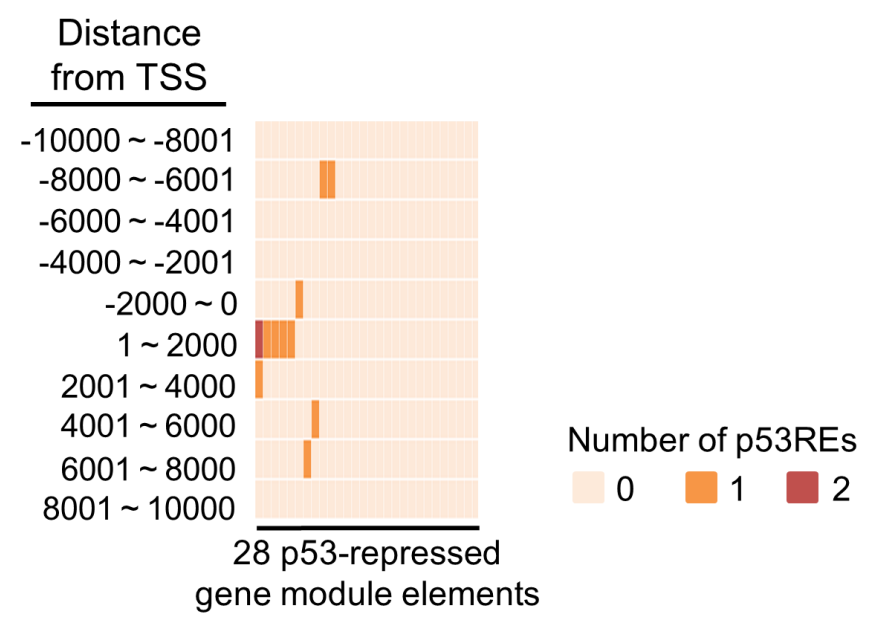

C

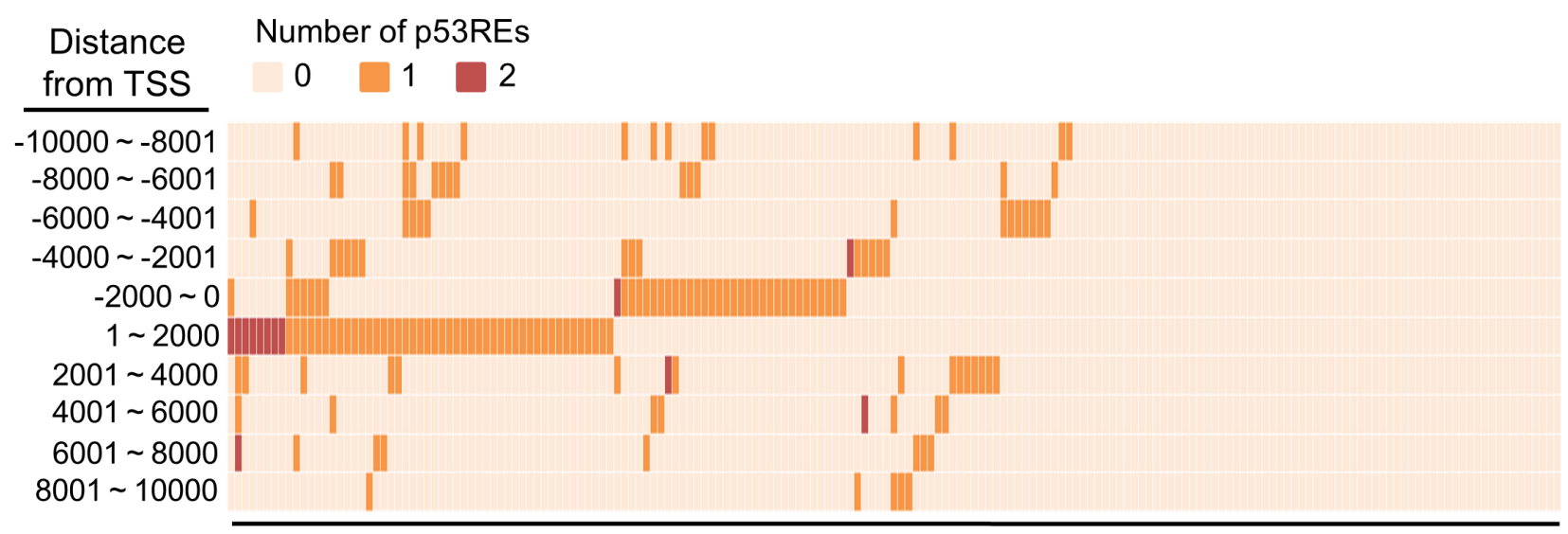

183 p53-induced genes

Figure 6: p53REs around TSS of p53-mediated genes. A. The number of p53 response elements (p53REs) in the promoter region of p53-mediated genes obtained from five different ADR-treated cells datasets in the database on human target gene regulation in the p53 and cell cycle networks is shown. B. The number of p53REs around TSS of p53-repressed gene module obtained from ReMap database is shown. C. The number of p53REs around TSS of p53-induced genes obtained from the ReMap database is shown. 
40]. To determine whether $\mathrm{p} 21 / \mathrm{CDKN} 1 \mathrm{~A}$ is required for the suppression of the p53-repressed gene module, p21/CDKN1A in HBC4 cells was silenced using small interfering RNA (siRNA). We found that knockdown of p21/CDKN1A attenuated the ADR-induced suppression of the p53-repressed gene module compared to control cells treated with siEGFP (Figure 7 and Supplementary Figure S6), which suggested that p21/CDKN1A was, at least partially, involved in the regulation of the p53-repressed gene module. Of note, knockdown of $p 21 / C D K N 1 A$ had no effect on the ADR-induced suppression of $P L K 1$ and RACGAP1 in HBC4 cells (Figure 7).

To further examine the effect of p21/CDKN1A on the regulation of $\mathrm{p} 53$-repressed gene module, colorectal cancer HCT116 $p 21^{-/-}$cells and their wild-type counterparts were subjected to qPCR analysis. Although HCT116 p21/cells retained the genotoxic stress-induced transactivation activity of p53 as measured by the FAS levels, which
PLK1

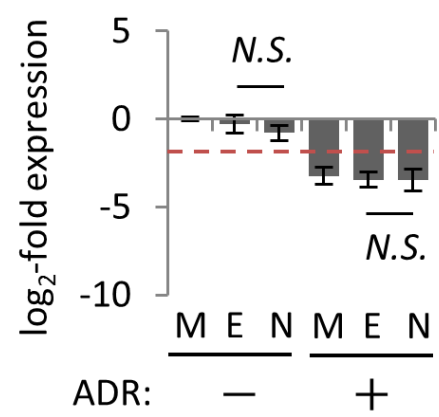

CCNB2

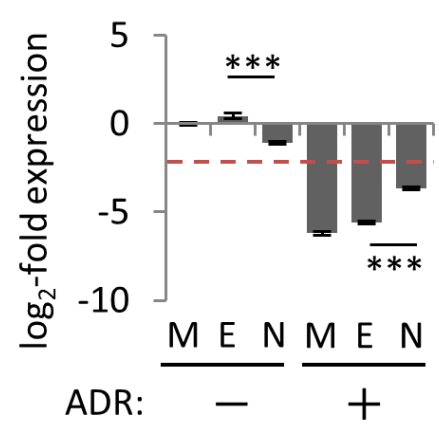

CEP55

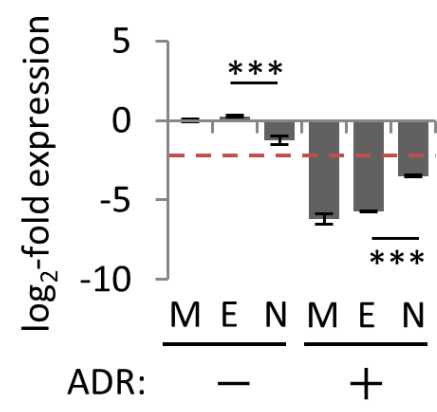

BIRC5

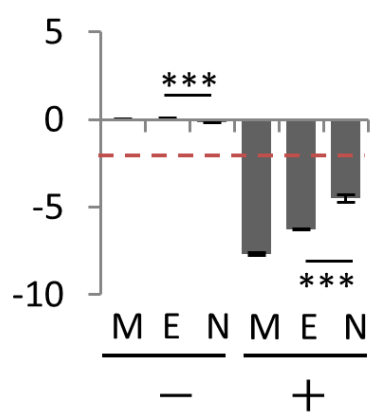

UBE2C

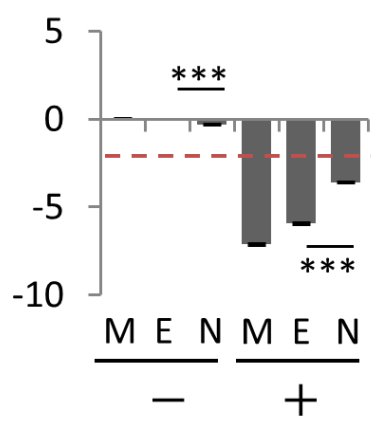

CDCA8

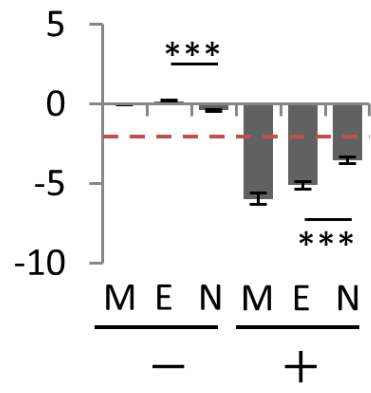

RACGAP1

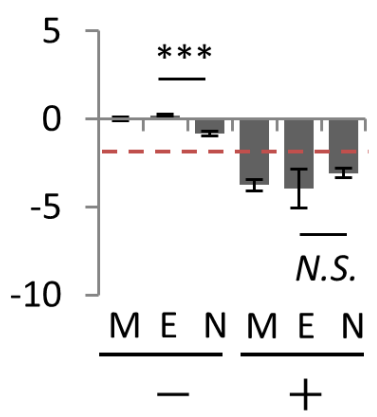

CCNB1

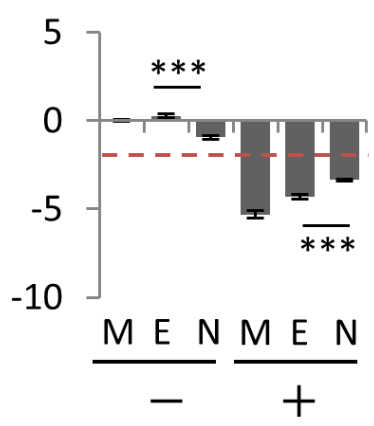

CENPA

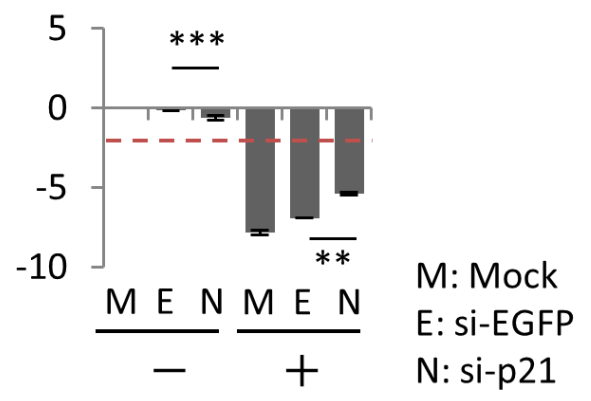

Figure 7: Effect of p21/CDKN1A knockdown on the regulation of p53-repressed gene module. At 24 hours after transfection of indicated siRNA, HBC4 cells were treated with $2 \mu \mathrm{g} / \mathrm{ml}$ ADR for 2 hours. Forty-eight hours after treatment, the mRNA expression level of the indicated genes was determined using qPCR, and the $\log _{2}$-fold change of mRNA expression against the control condition (Mock, no ADR treatment) was calculated using the $\Delta \Delta \mathrm{Ct}$ method. The data are presented as the mean $\pm \mathrm{SD}$ from three independent experiments. The red dotted line shows the cutoff value. ${ }^{*} P P<0.01, * * * P<0.001, N . S$., not statistically significant. Representative data ( 9 genes) are presented. Additional data are shown in Supplementary Figure S6. 
PLK1

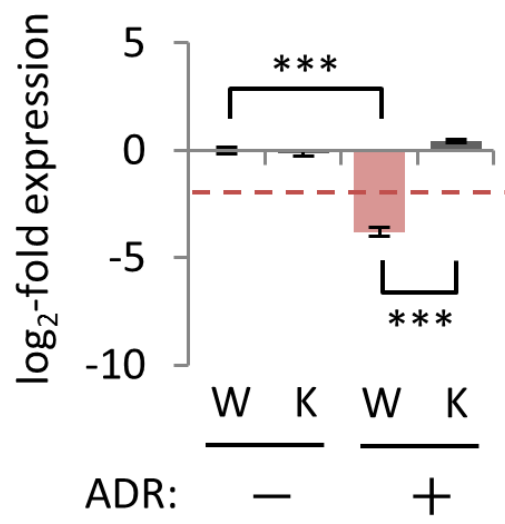

CCNB2

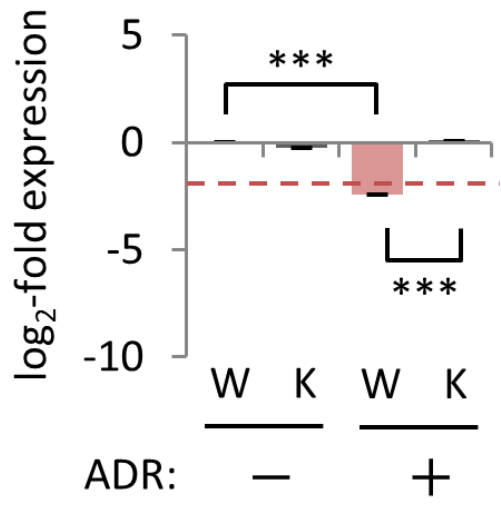

CEP55

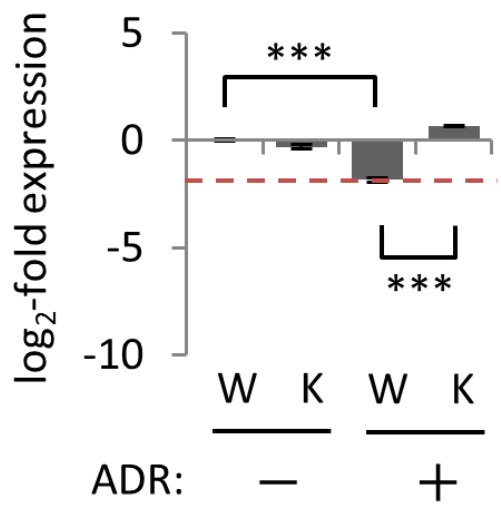

BIRC5

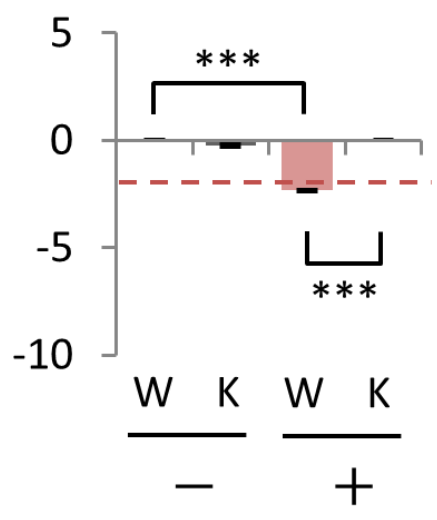

UBE2C

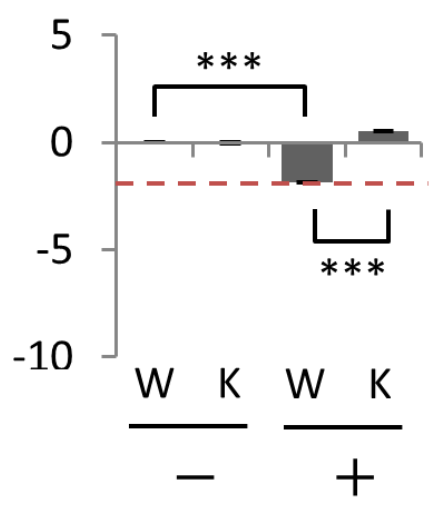

CDCA8

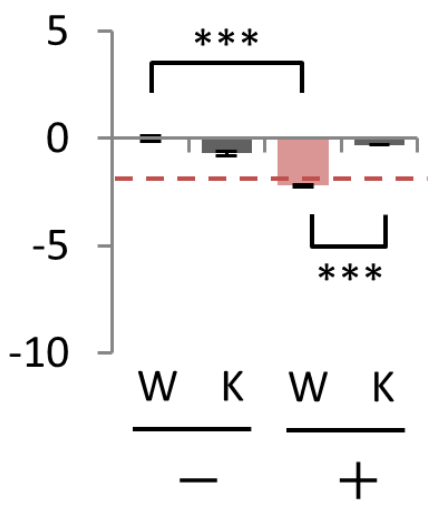

RACGAP1

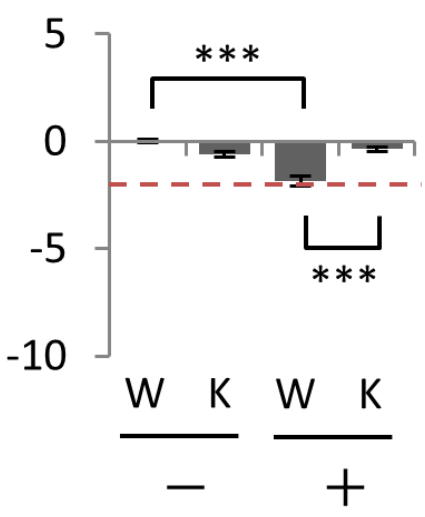

\section{CCNB1}

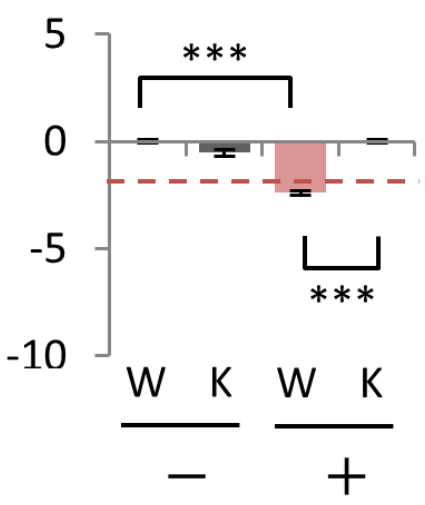

\section{CENPA}

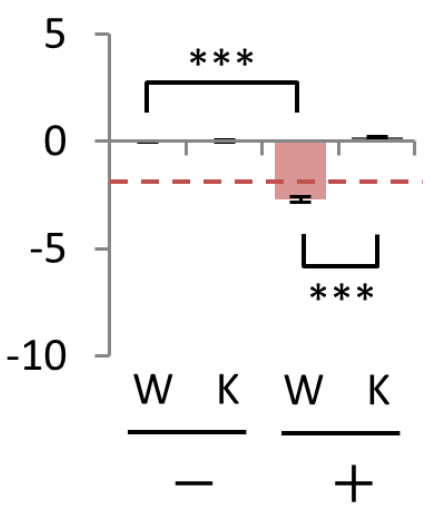

Figure 8: Effect of p21/CDKN1A knockout on the regulation of p53-repressed gene module. HCT116 $p 21^{+/+}$cells (W) and $p 21^{-\digamma}$ cells $(\mathrm{K})$ were treated with $2 \mu \mathrm{g} / \mathrm{ml}$ ADR for 2 hours. Forty-eight hours after treatment, the mRNA expression level of the indicated genes was determined using qPCR, and the $\log _{2}$-fold change of mRNA expression against the control condition $\left(\mathrm{HCT} 116 p 21^{+/+}\right.$cells, no ADR treatment) was calculated using the $\Delta \Delta \mathrm{Ct}$ method. The data are presented as the mean $\pm \mathrm{SD}$ from three independent experiments. The red dotted line shows the cutoff value. Red graph: lower than cutoff value. $* * * P<0.001, N$.S., not statistically significant. Representative data (9 genes) are presented. Additional data are shown in Supplementary Figure S7. 
is a major p53 target gene [41], the expression level of p21/CDKN1A mRNA was abrogated (Supplementary Figure S7). Under genotoxic stress, we found that 17 of the 28 p53-repressed gene module (AURKB, BIRC5, CCNA2, CCNB1, CCNB2, CDC20, CDCA3, CDCA8, CENPA, HMGB2, KIF11, LMNB1, MKI67, NDC80,
NUF2, PLK1, and PRC1) were suppressed in HCT116 $p 21^{+/+}$cells (Figure 8 and Supplementary Figure S7). Suppression of all 17 genes was disinhibited in ADRtreated HCT116 $p 21^{-/-}$cells compared to ADR-treated HCT $116 p 21^{+/+}$cells (Figure 8 and Supplementary Figure S7). Importantly, the effect of p21 perturbation on the
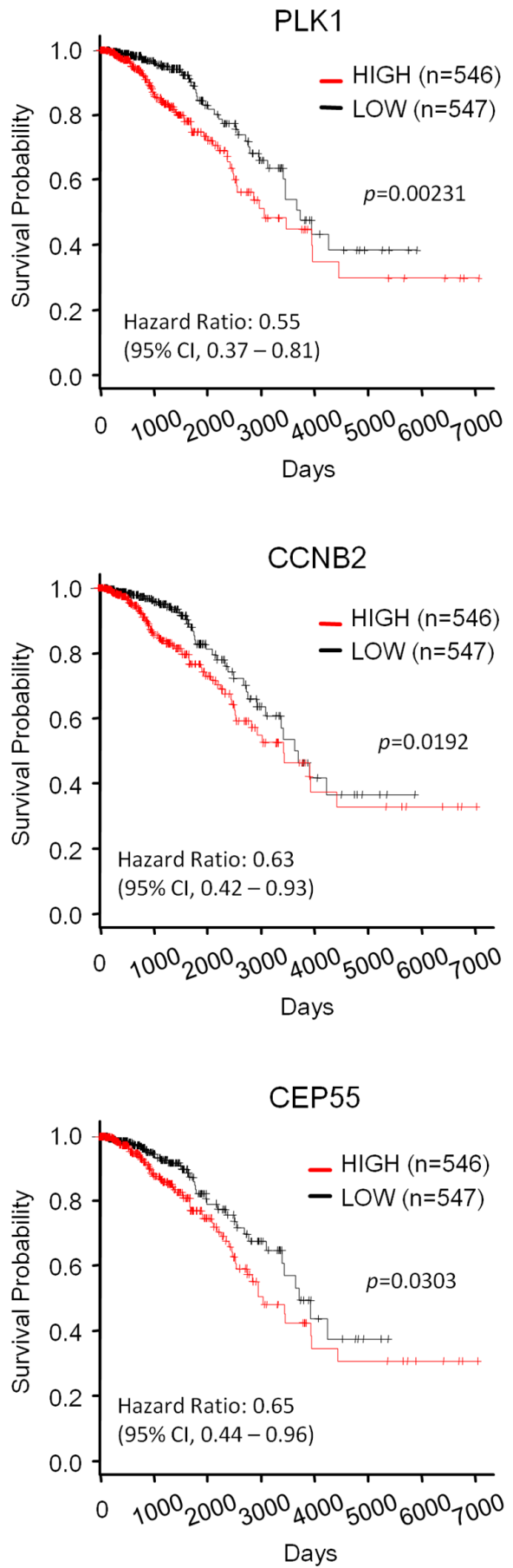
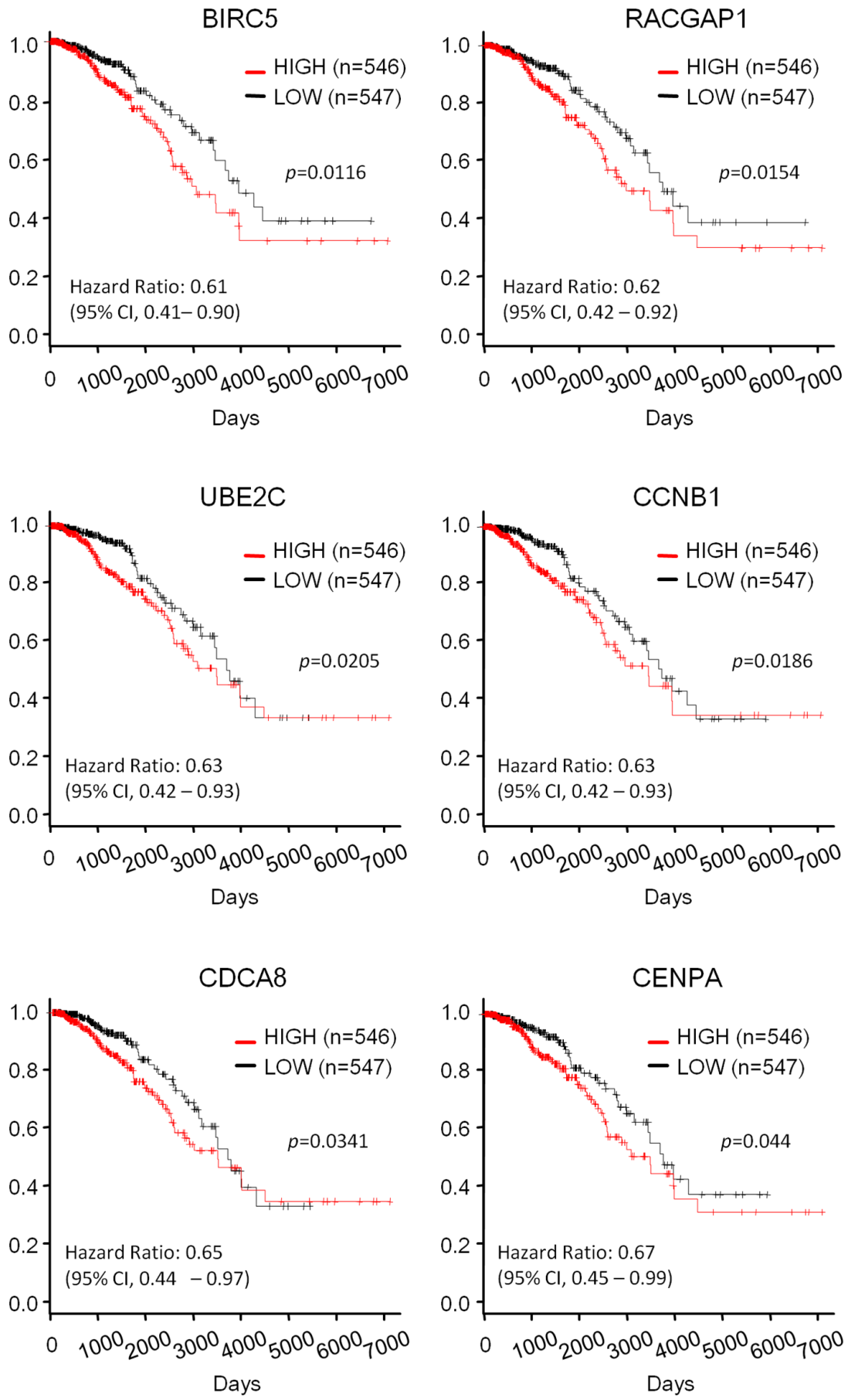

Figure 9: The relationship between the expression level of p53-mediated genes and prognosis of breast cancer patients. Kaplan-Meier survival curves of the higher expression group and lower expression group for the indicated genes. $P$-values were calculated using the log-rank test. 
ADR-induced suppression of p53-repressed gene module differed between HBC4 cells and HCT116 p21/- cells. Specifically, genotoxic stress-induced $P L K 1$ suppression was significantly disinhibited in HCT116 $p 21^{-/-}$cells, but not in $p 21 / C D K N 1 A$-knockdown HBC4 cells (Figures 7 and 8 ). Taken together, these results suggested that the mechanism of p53-mediated suppression for a specific gene (e.g. PLK1) is different among cell types and/or tissues.

\section{The importance of the p53-repressed gene module for the prognosis of breast cancer}

In breast cancer, p53 mutations are associated with worse overall survival [42]. We assessed whether p53repressed gene module affects the prognosis of breast cancer. Breast cancer patients in the TCGA dataset were subdivided into two groups: a higher expression group (High) and a lower expression group (Low) of the corresponding p53-repressed gene module. The median mRNA expression level was used as the cutoff value. As a result, we found that 9 of the 28 p53-repressed gene module correlated with survival outcome among breast cancer patients in a statistically significant manner (Figure 9). Fisher's exact test of independence confirmed that mutant p53 was significantly associated with the elevated expression of the 9 p53-repressed genes (Supplementary Figure S8). These results suggested that p53 mutations affected the patients' prognosis via perturbation of the p53-repressed gene module.

\section{DISCUSSION}

To date, some breast cancer predisposition genes have been identified [43]; among them, the transcription factor $p 53$ is commonly mutated in both breast cancers and other cancers [1, 44]. Thus, the rationale for developing attractive breast cancer therapies that target p53 is to reconstitute the most crucial p53 signaling network, which is indispensable for the operation of the p53regulated tumor suppression system. To achieve this goal, we focused on the identification of p53-repressed genes because potential p53-repressed genes remain poorly known compared with p53-induced genes [11]. Consequently, we identified 44 genes as common p53repressed genes. Among these, 28 genes (including 17 previously reported p53-repressed genes) were identified as the p53-repressed gene module that respond to genotoxic stress simultaneously in breast cancer cells, as verified by qPCR. GO analysis indicated that these genes are involved in the regulation of various cellular functions in a coordinated manner, suggesting that simultaneity is a key concept in the orchestration of p53 functions under particular conditions.

Notably, 4 genes (CDT1, FMNL1, NCAPD2, and SMC4) were not suppressed by overexpression of wild-type p53 (Figure 4), despite having exhibited p53dependent repression in response to genotoxic stress (Supplementary Figure S4). One potential reason is that the p53 mutant inhibited wild-type p53-mediated repression of these genes. Future studies may reveal the negating effects of the p53 mutants [45] on wild-type p53mediated gene repression.

Simultaneous suppression of the 28 gene elements was also observed in previously reported database [36], including Nutlin-3a-treated MCF-7 breast cancer cells, HepG2 liver cancer cells, IMR90 fetal lung fibroblasts, and HCT116 colorectal cancer cells as well as ADRtreated GM00011 fetal skin fibroblasts. These results suggested that the p53-repressed gene module identified in this study might function as a core module of p53repressed genes under various conditions and/or cell lines. Of note, 18 of the 28 p53-repressed genes were assigned as essential genes for optimal cell proliferation in chronic myelogenous leukemia cell lines [46]. Thus, fine-tuning and coordination of expression of each gene may be required to appropriately execute p53-mediated cellular functions. Future studies will reveal which p53 target genes are transactivated under a specific condition as the p53-mediated gene module and which p53-mediated gene module is a prerequisite to execute p53-regulated cellular functions.

It is well established that p53 transactivates the expression of p53-induced genes by binding to p53REs near the TSS of target genes [36]. However, the regulatory mechanisms of p53-mediated repression have little in common with the mechanisms of p53mediated transactivation. Indeed, there are various mechanisms by which p53 represses the expression of its downstream targets; these mechanisms can be divided into two categories: p53-dependent or p21/CDKN1Adependent repression systems [34, 47]. In the p53dependent repression system, p53 competes with other transcription factors or functions as a scaffold protein to recruit chromatin-remodeling factors to modify histone methylation status [47]. In addition, p53 promotes DNA methylation and inhibits the expression of large families of interspersed and tandem repeats [48]. However, the regulatory mechanisms of $\mathrm{p} 53$-dependent repression systems remain to be determined. As an alternative to the p53-dependent repression systems, computational meta-analysis of genome-wide data revealed that $\mathrm{p} 21 /$ CDKN1A-dependent repression system (e.g. the p53-p21DREAM/RB pathway) is a core system or is potentially the only system to suppress the expression of downstream p53-repressed genes [35]. Indeed, we also demonstrated that $\mathrm{p} 21 / \mathrm{CDKN} 1 \mathrm{~A}$ plays a pivotal role in suppressing the expression of the p53-repressed gene module in breast cancer cells. However, we found that p21/CDKN1A may not be the only node connecting p53 and p53repressed genes. For example, suppression of PLK1 did 
not disinhibit in $p 21 / C K D N 1 A$-silenced HBC4 cells under genotoxic stress (Figure 7), whereas the $P L K 1$ suppression was obviously disinhibited in HCT116 $p 21^{-/}$cells (Figure $8)$. Thus, we hypothesized that the regulatory mechanism of p53-repressed genes is different among cell types even for the same gene. Consistent with these findings, our p53 mouse dataset indicated that the regulation of the p53-repressed gene module showed a tissue-specific pattern. Further experiments are necessary to uncover the molecular mechanism underlying the repression of p53 downstream genes.

In conclusion, we identified 28 p53-repressed genes that were simultaneously suppressed in breast cancer cells under genotoxic stress (Supplementary Figure S9). The p53-repressed gene module in breast cancer cells is, at least partially, in the p21/CDKN1A-dependent suppression system. Furthermore, multi-tissue analysis of the p53-repressed gene module showed that the extent of suppression varied among tissues as well as genes. Our findings provide insight into a novel gene regulatory network to disentangle a complex p53 signaling network under both physiological and pathological conditions. In addition, a precise understanding of a p53-regulated gene module may eventually lead to profound insights into the treatment and/or cure of cancers where a p53-regulated gene module has gone awry.

\section{MATERIALS AND METHODS}

\section{Antibodies}

Anti-PLK1 antibody (sc-53751) was purchased from Santa Cruz Biotechnology. Anti-p53 (OP43) and anti-p21 (OP64) antibodies were obtained from MERCK MILLIPORE.

\section{Cell culture and treatment}

Human breast cancer cell line HBC4 cells were a kind gift from Dr. T. Yamori (The Cancer Institute of JFCR). HBL-100, MCF-7, ZR-75-1, T-47D, SKBR-3, and BT-549 human breast cancer cell lines were purchased from the American Type Culture Collection. HCT116 p $21^{+/+}$and HCT116 p2 $1^{-/}$cells lines were gifts from Prof. B. Vogelstein (Johns Hopkins University, USA). MCF10A $p 53^{+/+}$cells and MCF10A $p 53^{-/-}$cells were purchased from Sigma-Aldrich. HBL-100 cells were cultured in Dulbecco's modified Eagle's medium (DMEM; Gibco) supplemented with 10\% fetal bovine serum (FBS) and $1 \%$ penicillin/streptomycin at $37^{\circ} \mathrm{C}$ in 5\% $\mathrm{CO}_{2}$. HBC4, SK-BR-3, T-47D, BT-549, and ZR-75-1 cells were cultured in RPMI 1640 (Gibco) supplemented with $10 \% \mathrm{FBS}$ and $1 \%$ penicillin/streptomycin at $37^{\circ} \mathrm{C}$ in $5 \% \mathrm{CO}_{2}$. MCF-7 cells were cultured in minimum essential medium (MEM; Gibco) supplemented with 10\% FBS, $0.01 \mathrm{mg} / \mathrm{ml}$ bovine insulin, Non-Essential Amino Acids Solution (Gibco, cat\# 11140-050), sodium pyruvate (Gibco, cat\#11360-070), and 1\% penicillin/streptomycin at $37^{\circ} \mathrm{C}$ in $5 \% \mathrm{CO}_{2}$. MCF10A p $53^{+/+}$cells and MCF10A $p 53^{-/-}$cells were cultured in MEGM mammary epithelial cell growth medium (LONZA) supplemented with 100 $\mathrm{ng} / \mathrm{ml}$ cholera toxin at $37^{\circ} \mathrm{C}$ in $5 \% \mathrm{CO}_{2}$. HCT116 p2 $1^{+/+}$ and HCT116 p21/- cells were cultured in McCoy's 5a medium (Gibco) supplemented with 10\% FBS and $1 \%$ penicillin/streptomycin at $37^{\circ} \mathrm{C}$ in $5 \% \mathrm{CO}_{2}$. Small interfering RNA (siRNA) oligonucleotides, commercially synthesized by Sigma Genosys, were transfected with Lipofectamine RNAiMAX reagent (Invitrogen). Sequences of siRNA oligonucleotides are as follows. SiEGFP: forward, 5'-GCAGCACGACUUCUUCAAG-3'; reverse, 5'-CUUGAAGAAGUCGUGCUGC-3'. Si-p53: forward, 5'-GACUCCAGUGGUAAUCUAC-3'; reverse, 5'-GUAGAUUACCACUGGAGUC-3'. Si-p21/CDKN1A: forward, 5'- GAUGGAACUUCGACUUUGU-3'; reverse, 5'-ACAAAGUCGAAGUUCCAUC-3'. We generated and purified replication-deficient recombinant viruses expressing p53 (Ad-p53) or LacZ (Ad-LacZ) as previously described [49]. T-47D cells were infected with viral solutions at various multiplicities of infection (MOI) and incubated at $37^{\circ} \mathrm{C}$ until the time of harvest (48 hours). For treatment with genotoxic stress, cells were incubated with $2 \mu \mathrm{g} / \mathrm{ml}$ of ADR for $2 \mathrm{~h}$ and then cultured in fresh medium until the indicated time.

\section{cDNA microarray and its data processing}

Gene expression analysis was performed using a SurePrint G3 Human GE 8x60K microarray (Agilent, Santa Clara) according to the manufacturer's protocol. Briefly, MCF10A $p 53^{+/+}$and MCF10A $p 53^{-/-}$cells were treated with $0.5 \mu \mathrm{g} / \mathrm{ml}$ of ADR for 2 hours, then cultured with fresh medium by indicated time at $37^{\circ} \mathrm{C}$. At $0 \mathrm{~h}, 12 \mathrm{~h}$, $24 \mathrm{~h}$ and $48 \mathrm{~h}$ after ADR treatment, total RNA was isolated from the cells using RNeasy Plus Universal Mini Kits (Qiagen) according to the manufacturer's instructions. Each RNA sample was labeled and hybridized to array slides. For the selection of p53-repressed gene candidates, we filtered 47,534 peaks (derived from 22,276 genes) according to the following criteria for quantification of the mRNA abundance changes: (A) calculation of the median expression in ADR-treated MCF10A p $53^{+/+}$cells collected at $12 \mathrm{~h}$ (W12), $24 \mathrm{~h}$ (W24), and $48 \mathrm{~h}$ (W48) after the treatment; (B) calculation of minimum expression in following datasets: no treated MCF10A $p 53^{+/+}$cells $(0$ $\mathrm{h}, \mathrm{W} 0)$ and all MCF10A $p 53^{-/-}$cells datasets (K0, K12, $\mathrm{K} 24, \mathrm{~K} 48)$. As final p53-repressed gene candidates, genes whose $(\mathrm{A}) /(\mathrm{B})$ ratio $<0.5$ were extracted. The MCF10A microarray data is available from the NCBI GEO database (GSE98727). 


\section{Mice and X-ray treatment}

$p 53^{--}$mice were provided from the RIKEN BioResource Center. Genotypes were confirmed by PCR analysis. All mice were maintained under specific pathogen-free conditions and were handled according to the Guidelines for Animal Experiments of the Institute of Medical Science (University of Tokyo, Tokyo, Japan). $p 53^{+/+}$and $p 53^{-/-}$mice were X-ray-irradiated using the MBR-1520R-3 system (Hitachi). At $24 \mathrm{~h}$ after irradiation (10 Gy, total body irradiation), 24 tissues were collected from mice. The age and gender of mice were as follows: Bladder, Bone marrow, Cerebrum, Colon, Esophagus, Eyeball, Heart, Kidney, Liver, Lung, Muscle, Seminal vesicle, Small intestine, Spleen, Stomach, Testis, Thymus, and Tongue: male, 6 weeks, $n=3$ each, Bone: male, 1 week, $n=3$ each, Uterus: female, 10 weeks, $n=3$ each, Mammary gland and Ovary: female, 10 weeks, $n=2$ each. Tissues were preserved in RNAlater solution (QIAGEN) at $4{ }^{\circ} \mathrm{C}$ until RNA purification. Bone marrow was resolved in RLT plus reagent provided by the RNeasy Plus Mini Kit (QIAGEN) and homogenized using a QIAshredder column (QIAGEN). The lysates were stored at $-80^{\circ} \mathrm{C}$ until RNA purification.

\section{RNA sequencing and its data processing}

Experimental details are described in [50]. Tissues were homogenized in QIAzol lysis reagent (QIAGEN) using Precellys 24 (Bertin Corporation). Total RNA was recovered using the RNeasy Plus Universal Mini Kit (QIAGEN). For RNA extraction from bone marrow, we used the RNeasy Plus Mini Kit (QIAGEN). We selected 256 samples for RNA sequencing analysis based on RNA quality and quantity, which were evaluated using a Bioanalyzer (Agilent) and NanoDrop spectrophotometer (Thermo Scientific). High-quality RNA was subjected to polyA+ selection and chemical fragmentation, and a 100-200 base RNA fraction was used to construct complementary DNA libraries according to Illumina's protocol. RNA-seq was performed on a HiSeq 2500 using a standard paired-end 101-bp protocol. We used a tophat+cufflinks pipeline to process raw RNA-seq data. Before data processing, the quality of data was confirmed using FastQC. To quantify gene and transcript expression levels for all samples, we first aligned 101 bp paired-end reads to the mouse reference genome mm9/GRCm37 using Tophat (v2.0.9). The mapping parameters follow the default setting in the Tophat. After read mapping, the transcript and gene expression levels, which are represented by FPKM values, were calculated by Cufflinks (v2.2.1). For the selection of p53-repressed gene candidates, we filtered 23,282 genes according to the following criteria for quantification of the mRNA abundance changes after adding a count of one as a pseudocount: (A) calculation of the average expression in X-ray-irradiated $p 53^{+/+}$mice (WX); (B) calculation of the minimum expression in the following datasets: average expression in no irradiated $p 53^{+/+}$mice (W), average expression in X-ray-irradiated $p 53^{-/-}$mice $(\mathrm{KX})$, and average expression in no irradiated $p 53^{-/-}$mice $(\mathrm{K})$. As final p53-repressed gene candidates, genes whose (A)/ (B) ratio $<0.5$ were extracted. The raw data obtained in this study can be accessible in DDBJ database (http:// www.ddbj.nig.ac.jp/index-e.html) with accession number of DRA005768 with bioproject accession number of PRJDB5738.

\section{Data processing of breast cancer patients in the TCGA database}

The mRNA expression of genes, p53 mutation status, and clinical data were obtained from The Cancer Genome Atlas (TCGA) [12]. For the selection of p53repressed gene candidates, 1,093 breast cancer samples in the TCGA-BRCA dataset were divided into two groups according to the p53 mutation status (wild-type $p 53: n=$ 795; p53 mutation: $n=298$ ) and the average expression of each 20,475 genes was calculated. As final p53-repressed gene candidates, genes whose average expression in tumors harboring wild-type $p 53$ was significantly $(p<$ 0.05 ) lower than that in tumors harboring $p 53$ mutation were extracted.

\section{Quantitative real-time PCR}

Total RNA was isolated from human cells using RNeasy Plus Mini Kits (Qiagen) and RNeasy Plus Universal Mini Kits (Qiagen) according to the manufacturer's instructions. Complementary DNAs were synthesized using Super Script III reverse transcriptase (Invitrogen). Quantitative real-time PCR (qPCR) was performed using the SYBR Green Master Mix with a Light Cycler 480 instrument (Roche). For $\Delta \Delta \mathrm{Ct}$ method, $\beta$-actin was used as a reference gene. Fold expression change was calculated as $2^{-\Delta \Delta c t}$ according to the manufacturer's protocol. Primer sequences are listed in Supplementary Table S5.

\section{Western blot analysis}

Total cell lysates were prepared with lysis buffer containing $50 \mathrm{mM}$ Tris- $\mathrm{HCl}$ (pH 7.5), $100 \mathrm{mM} \mathrm{NaCl}, 1 \%$ NP-40, Protease Inhibitor Cocktail Set III (Calbiochem), and phosphatase inhibitor cocktail set II (MERCK MILLIPORE) and normalized by protein concentration using the BCA method (Thermo Scientific). The protein samples were separated on SDS-polyacrylamide gel electrophoresis and transferred to nitrocellulose 
membranes (Hybond ${ }^{\mathrm{TM}}$ ECL TM $^{\mathrm{TM}}$, Amersham). Membranes were blocked in TBS-T containing 5\% nonfat milk for 1 hour at room temperature. Then, the membranes were incubated with primary antibodies according to the manufacturer's instructions for 18 hours at $4^{\circ} \mathrm{C}$. After that, the membranes were incubated with horseradish peroxidase-conjugated goat anti-mouse IgG (Santa Cruz Biotechnology) and visualized by chemiluminescent detection (Immobilon, Millipore).

\section{Statistical analysis}

Statistical analysis was performed using an unpaired two-tailed Student's $t$-test. The F-test was used to determine whether variances were equal or unequal. 1,093 patients in TCGA-BRCA dataset from TCGA were subjected for the statistical analysis. Survival analysis was performed by Kaplan-Meier method using EZR (v.1.27) software. Hazard ratio was calculated by using EZR (v.1.27) software. Fisher's exact test was performed using EZR (v.1.27) software. A $p$-value of $<0.05$ was considered statistically significant.

\section{Author contributions}

M.K. conceived the project.; M.K. and M.T. designed the experiments.; M.T., C.T., V.Y., Y.Z., S.I., R.Y., S.M., and H.N. conducted the experiments.; M.T. and M.K. wrote the manuscript.

\section{ACKNOWLEDGMENTS}

We thank Satomi Takahashi and Misato Oshima for their technical assistance.

\section{CONFLICTS OF INTEREST}

The authors declare no conflicts of interest.

\section{FUNDING}

The research was supported by Grant-in-Aid for Scientific Research on Innovative Areas (16H01566, 25134707, and 15H0912).

\section{REFERENCES}

1. Coles C, Condie A, Chetty U, Steel CM, Evans HJ, Prosser J. p53 mutations in breast cancer. Cancer Res. 1992; 52:5291-98.

2. Ingvarsson S. Molecular genetics of breast cancer progression. Semin Cancer Biol. 1999; 9:277-88.

3. Petrucelli N, Daly MB, Feldman GL. Hereditary breast and ovarian cancer due to mutations in BRCA1 and BRCA2.
Genet Med. 2010; 12:245-59.

4. Tan MH, Mester JL, Ngeow J, Rybicki LA, Orloff MS, Eng C. Lifetime cancer risks in individuals with germline PTEN mutations. Clin Cancer Res. 2012; 18:400-07.

5. Lacroix M, Leclercq G. The "portrait" of hereditary breast cancer. Breast Cancer Res Treat. 2005; 89:297-304.

6. van der Post RS, Vogelaar IP, Carneiro F, Guilford P, Huntsman D, Hoogerbrugge N, Caldas C, Schreiber KE, Hardwick RH, Ausems MG, Bardram L, Benusiglio PR, Bisseling TM, et al. Hereditary diffuse gastric cancer: updated clinical guidelines with an emphasis on germline CDH1 mutation carriers. J Med Genet. 2015; 52:361-74.

7. Hisada M, Garber JE, Fung CY, Fraumeni JF Jr, Li FP. Multiple primary cancers in families with Li-Fraumeni syndrome. J Natl Cancer Inst. 1998; 90:606-11.

8. Hearle N, Schumacher V, Menko FH, Olschwang S, Boardman LA, Gille JJ, Keller JJ, Westerman AM, Scott RJ, Lim W, Trimbath JD, Giardiello FM, Gruber SB, et al. Frequency and spectrum of cancers in the Peutz-Jeghers syndrome. Clin Cancer Res. 2006; 12:3209-15.

9. Forbes SA, Tang G, Bindal N, Bamford S, Dawson E, Cole C, Kok CY, Jia M, Ewing R, Menzies A, Teague JW, Stratton MR, Futreal PA. COSMIC (the Catalogue of Somatic Mutations in Cancer): a resource to investigate acquired mutations in human cancer. Nucleic Acids Res. 2010; 38:D652-7.

10. Bieging KT, Mello SS, Attardi LD. Unravelling mechanisms of p53-mediated tumour suppression. Nat Rev Cancer. 2014; 14:359-70.

11. Riley T, Sontag E, Chen P, Levine A. Transcriptional control of human p53-regulated genes. Nat Rev Mol Cell Biol. 2008; 9:402-12.

12. Cancer Genome Atlas Research Network, Weinstein JN, Collisson EA, Mills GB, Shaw KR, Ozenberger BA, Ellrott K, Shmulevich I, Sander C, Stuart JM. The Cancer Genome Atlas Pan-Cancer analysis project. Nat Genet. 2013; 45:1113-20.

13. Schlereth K, Heyl C, Krampitz AM, Mernberger M, Finkernagel F, Scharfe M, Jarek M, Leich E, Rosenwald A, Stiewe T. Characterization of the p53 cistrome-DNA binding cooperativity dissects p53's tumor suppressor functions. PLoS Genet. 2013; 9:e1003726.

14. Hoffman WH, Biade S, Zilfou JT, Chen J, Murphy M. Transcriptional repression of the anti-apoptotic survivin gene by wild type p53. J Biol Chem. 2002; 277:3247-57.

15. Fischer M, Quaas M, Steiner L, Engeland K. The p53-p21DREAM-CDE/CHR pathway regulates $\mathrm{G} 2 / \mathrm{M}$ cell cycle genes. Nucleic Acids Res. 2016; 44:164-74.

16. Quaas M, Müller GA, Engeland K. p53 can repress transcription of cell cycle genes through a p21(WAF1/ CIP1)-dependent switch from MMB to DREAM protein complex binding at CHR promoter elements. Cell Cycle. 2012; 11:4661-72.

17. Kidokoro T, Tanikawa C, Furukawa Y, Katagiri T, 
Nakamura Y, Matsuda K. CDC20, a potential cancer therapeutic target, is negatively regulated by p53. Oncogene. 2008; 27:1562-71.

18. Date DA, Jacob CJ, Bekier ME, Stiff AC, Jackson MW, Taylor WR. Borealin is repressed in response to $\mathrm{p} 53 / \mathrm{Rb}$ signaling. Cell Biol Int. 2007; 31:1470-81.

19. Scian MJ, Carchman EH, Mohanraj L, Stagliano KE, Anderson MA, Deb D, Crane BM, Kiyono T, Windle B, Deb SP, Deb S. Wild-type p53 and p73 negatively regulate expression of proliferation related genes. Oncogene. 2008; 27:2583-93.

20. Chang YC, Wu CH, Yen TC, Ouyang P. Centrosomal protein 55 (Cep55) stability is negatively regulated by p53 protein through Polo-like kinase 1 (Plk1). J Biol Chem. 2012; 287:4376-85.

21. Fischer M, Grundke I, Sohr S, Quaas M, Hoffmann S, Knörck A, Gumhold C, Rother K. p53 and cell cycle dependent transcription of kinesin family member 23 (KIF23) is controlled via a CHR promoter element bound by DREAM and MMB complexes. PLoS One. 2013; 8:e63187.

22. Freund A, Laberge RM, Demaria M, Campisi J. Lamin B1 loss is a senescence-associated biomarker. Mol Biol Cell. 2012; 23:2066-75.

23. Hammond EM, Mandell DJ, Salim A, Krieg AJ, Johnson TM. Shirazi H a, Attardi LD, Giaccia AJ. Genome-wide analysis of p53 under hypoxic conditions. Mol Cell Biol. 2006; 26:3492-504.

24. McKenzie L, King S, Marcar L, Nicol S, Dias SS, Schumm K, Robertson P, Bourdon JC, Perkins N, Fuller-Pace F, Meek DW. p53-dependent repression of polo-like kinase-1 (PLK1). Cell Cycle. 2010; 9:4200-12.

25. Iannetti A, Ledoux AC, Tudhope SJ, Sellier H, Zhao B, Mowla S, Moore A, Hummerich H, Gewurz BE, Cockell SJ, Jat PS, Willmore E, Perkins ND. Regulation of p53 and $\mathrm{Rb}$ links the alternative NF- $\mathrm{\kappa B}$ pathway to EZH2 expression and cell senescence. PLoS Genet. 2014; 10:e1004642.

26. Carvajal LA, Hamard PJ, Tonnessen C, Manfredi JJ. E2F7, a novel target, is up-regulated by p53 and mediates DNA damage-dependent transcriptional repression. Genes Dev. 2012; 26:1533-45.

27. Wang Q, Zambetti GP, Suttle DP. Inhibition of DNA topoisomerase II alpha gene expression by the p53 tumor suppressor. Mol Cell Biol. 1997; 17:389-97.

28. Bajaj S, Alam SK, Roy KS, Datta A, Nath S, Roychoudhury S. E2 ubiquitin-conjugating enzyme, UBE2C gene, is reciprocally regulated by wild-type and gain-of-function mutant p53. J Biol Chem. 2016; 291:14231-47.

29. Wang X, Dalkic E, Wu M, Chan C. Gene module level analysis: identification to networks and dynamics. Curr Opin Biotechnol. 2008; 19:482-91.

30. Saint-Ruf C, Nardeux P, Cebrian J, Lacasa M, Lavialle C, Cassingena R. Molecular cloning and characterization of endogenous SV40 DNA from human HBL-100 cells. Int J
Cancer. 1989; 44:367-72.

31. Sheppard HM, Corneillie SI, Espiritu C, Gatti A, Liu X. New insights into the mechanism of inhibition of p53 by simian virus 40 large T antigen. Mol Cell Biol. 1999; 19:2746-53.

32. Huang W, Sherman BT, Lempicki RA. Systematic and integrative analysis of large gene lists using DAVID bioinformatics resources. Nat Protoc. 2009; 4:44-57.

33. Gudkov AV, Komarova EA. The role of 553 in determining sensitivity to radiotherapy. Nat Rev Cancer. 2003; 3:11729.

34. Ho J, Benchimol S. Transcriptional repression mediated by the p53 tumour suppressor. Cell Death Differ. 2003; 10:404-08.

35. Fischer M, Steiner L, Engeland K. The transcription factor p53: not a repressor, solely an activator. Cell Cycle. 2014; 13:3037-58.

36. Fischer M, Grossmann P, Padi M, DeCaprio JA. Integration of TP53, DREAM, MMB-FOXM1 and RB-E2F target gene analyses identifies cell cycle gene regulatory networks. Nucleic Acids Res. 2016; 44:6070-86.

37. Griffon A, Barbier Q, Dalino J, van Helden J, Spicuglia $\mathrm{S}$, Ballester B. Integrative analysis of public ChIP-seq experiments reveals a complex multi-cell regulatory landscape. Nucleic Acids Res. 2015; 43:e27.

38. Spitkovsky D, Schulze A, Boye B, Jansen-Dürr P. Downregulation of cyclin $\mathrm{A}$ gene expression upon genotoxic stress correlates with reduced binding of free E2F to the promoter. Cell Growth Differ. 1997; 8:699-710.

39. Azzam EI, de Toledo SM, Pykett MJ, Nagasawa H, Little JB. CDC2 is down-regulated by ionizing radiation in a p53dependent manner. Cell Growth Differ. 1997; 8:1161-69.

40. Gottifredi V, Karni-Schmidt O, Shieh SS, Prives C. p53 down-regulates CHK1 through $\mathrm{p} 21$ and the retinoblastoma protein. Mol Cell Biol. 2001; 21:1066-76.

41. Müller M, Wilder S, Bannasch D, Israeli D, Lehlbach K, LiWeber M, Friedman SL, Galle PR, Stremmel W, Oren M, Krammer PH. p53 activates the CD95 (APO-1/Fas) gene in response to DNA damage by anticancer drugs. J Exp Med. 1998; 188:2033-45.

42. Pharoah PD, Day NE, Caldas C. Somatic mutations in the p53 gene and prognosis in breast cancer: a meta-analysis. Br J Cancer. 1999; 80:1968-73.

43. Martin AM, Weber BL. Genetic and hormonal risk factors in breast cancer. J Natl Cancer Inst. 2000; 92:1126-35.

44. Gasco M, Shami S, Crook T. The p53 pathway in breast cancer. Breast Cancer Res. 2002; 4:70-76.

45. Willis A, Jung EJ, Wakefield T, Chen X. Mutant p53 exerts a dominant negative effect by preventing wild-type p53 from binding to the promoter of its target genes. Oncogene. 2004; 23:2330-38.

46. Wang T, Birsoy K, Hughes NW, Krupczak KM, Post Y, Wei JJ, Lander ES, Sabatini DM. Identification and characterization of essential genes in the human genome. 
Science. 2015; 350:1096-101.

47. Rinn JL, Huarte M. To repress or not to repress: this is the guardian's question. Trends Cell Biol. 2011; 21:344-53.

48. Leonova KI, Brodsky L, Lipchick B, Pal M, Novototskaya L, Chenchik AA, Sen GC, Komarova EA, Gudkov AV. p53 cooperates with DNA methylation and a suicidal interferon response to maintain epigenetic silencing of repeats and noncoding RNAs. Proc Natl Acad Sci USA. 2013; 110:E89-98.
49. Oda K, Arakawa H, Tanaka T, Matsuda K, Tanikawa C, Mori T, Nishimori H, Tamai K, Tokino T, Nakamura Y, Taya Y. p53AIP1, a potential mediator of p53-dependent apoptosis, and its regulation by Ser-46-phosphorylated p53. Cell. 2000; 102:849-62.

50. Tanikawa C, Zhang YZ, Yamamoto R, Tsuda Y, Tanaka M, Funauchi Y, Mori J, Imoto S, Yamaguchi R, Nakamura Y, Miyano S, Nakagawa H, Matsuda K. The Transcriptional Landscape of p53 Signalling Pathway. EBioMedicine. 2017; 20:109-19. 